\title{
Molecular assembly of plasminogen and tissue-type plasminogen activator on an evolving fibrin surface
}

\author{
Valérie FLEURY ${ }^{1}$, Stéphane LOYAU ${ }^{1}$, H. Roger LIJNEN ${ }^{2}$, Willem NIEUWENHUIZEN ${ }^{3}$ and Eduardo ANGLÉS-CANO \\ 1 Institut National de la Santé et de la Recherche Médicale, Unité 143, Centre Hospitalo-Universitaire of Bicêtre, France \\ 2 Center for Molecular and Vascular Biology, University of Leuven, Belgium \\ ${ }^{3}$ Gaubius Laboratory IVVO-TNO, Leiden, The Netherlands
}

(Received March 17/June 29, 1993) - EJB 93 0394/2

A well characterized model of an intact and a degraded surface of fibrin that represents the states of fibrin during the initiation and the progression of fibrinolysis was used to quantitatively characterize the molecular interplay between tissue-type plasminogen activator (t-PA), plasminogen and fibrin. The molecular assembly of t-PA and plasminogen on these surfaces was investigated using combinations of proteins that preclude complications due to side reactions caused by generated plasmin: native plasminogen with di-isopropylphosphofluoridate-inactivated $\mathrm{t}-\mathrm{PA}$, and a recombinant human plasminogen with the active-site Ser741 mutagenized to Ala which renders the catalytic site inactive. Under these conditions, neither the affinity nor the maximal number of binding sites for plasminogen were modified by the presence of t-PA, indicating that binding sites for plasminogen pre-exist in intact fibrin and are not dependent on the presence of t-PA. In contrast, when plasminogen activation is allowed, increasing binding of plasminogen to the progressively degraded fibrin surface is directly correlated $(r=0.98)$ to the appearance of the fibrin E-fragment as shown using a monoclonal antibody (FDP-14) that has its epitope in the E domain of fibrin. t-PA was shown to bind with a high affinity to both the intact $\left(K_{\mathrm{d}}=3.3 \pm 0.6 \mathrm{nM}\right)$ and the degraded surface of fibrin $\left(K_{\mathrm{d}}=1.2 \pm 0.4 \mathrm{nM}\right)$. Binding of t-PA to carboxy-terminal lysine residues of degraded fibrin was shown to be efficiently competed by physiological concentrations of plasminogen $(2 \mu \mathrm{M})$, indicating that the affinity of t-PA for these residues was lower than that of plasminogen $\left(K_{\mathrm{b}}=\right.$ $0.66 \pm 0.22 \mu \mathrm{M}$ ) and unrelated to the high affinity of t-PA for specific binding sites on intact fibrin. These data confirm and establish that the generation of carboxy-terminal lysine residues on fibrin during ongoing fibrinolysis, and the binding of plasminogen to these sites, is an important pathway in the acceleration of clot dissolution.

Intravascular fibrinolysis is a heterogeneously catalyzed process triggered by tissue-type plasminogen activator (t-PA) [1], and evolving from the plasma/fibrin interface to the interior of the clot [2]. In this process, polymerized fibrin acts both as a stimulator of t-PA activity and as a substrate for in situ generated plasmin.

Correspondence to E. Anglés-Cano, INSERM Unité 143, Hôpital de Bicêtre, I. P. C., F-94275-Cedex, Bicêtre, France

Fax: +33146706446 .

Abbreviations. t-PA, tissue-type plasminogen activator; Dip-tPA, t-PA with its catalytic site inactivated with di-isopropylphosphofluoridate; tcu-PA, two-chain urokinase-type plasminogen activator; Glu-plasminogen, native human plasminogen with amino-terminal glutamic acid; [Ala741]rPg, recombinant plasminogen with Ser741 mutagenized to Ala; LBS, lysine-binding site; AH, aminohexyl; ${ }_{\mathrm{iPr}} \mathrm{P}-\mathrm{F}$, di-isopropylphosphofluoridate; 6-AHA, 6-aminohexanoic acid; ValPheLys $\mathrm{CH}_{2} \mathrm{Cl}$, D-valyl-L-phenylalanyl-L-lysine chloromethane; Dns-GluGlyArgCH${ }_{2} \mathrm{Cl}$, dansyl-glutamyl-glycyl-arginine chloromethane; PheProArgCH $\mathrm{CH}_{2} \mathrm{Cl}$, D-phenylalanyl-L-prolyl-L-arginine chloromethane.

Enzymes. t-PA (EC 3.4.21.68); teu-PA (EC 3.4.21.73); plasmin (EC 3.4.21.7); thrombin (EC 3.4.21.5); carboxypeptidase B (EC 3.4.17.2).
The efficiency and specificity of the fibrinolytic process are based on the assembly of t-PA and its substrate, plasminogen, at the fibrin surface [3]. The amino-terminal regions of plasminogen [4] and t-PA [5, 6] contain structural domains that govern their affinity for fibrin. Thus, the binding of plasminogen is mediated by interactions between the lysine-binding sites (LBS) of the kringle domains and lysine residues in other proteins. High-affinity LBS have been identified on kringles 1 and $4[7-10]$, and a low-affinity binding site, called aminohexyl-binding site (AH-binding site) has been demonstrated on kringle $5[11,12]$. A LBS of moderate affinity for fibrin has also been characterized on the kringle 2 domain of t-PA [13]; however, the nature of the interaction between the finger domain of t-PA and fibrin remains unknown. A mechanism that amplifies and accelerates fibrinolysis has been described [14]. This mechanism is mediated by the initial limited degradation of the surface of fibrin by plasmin which generates carboxy-terminal lysine residues that constitute new binding sites for plasminogen. TranThang et al. [15, 16] and Harpel et al. [17] have suggested that the initial binding of t-PA may increase the binding of plasminogen by a similar mechanism. 
From competitive binding experiments performed with the use of a static model of limited plasmin-digested fibrin, De Vries et al. [18] have concluded that t-PA and Glu-plasminogen may compete for carboxy-terminal lysines, whereas on intact fibrin, plasminogen and t-PA may bind to distinct and independent sites. However, molecular interactions occurring between fibrinolytic proteins and progressively degraded fibrin residues appearing during ongoing fibrinolysis escape direct detection. This is the reason why the assembly of plasminogen and t-PA on the fibrin surface during fibrinolysis has not been fully characterized. We have developed a stable model of an evolving fibrin surface that allows such studies. With the use of this model, we have previously quantitatively characterized the role of carboxy-terminal lysine residues on progressively degraded fibrin in the binding of plasminogen [19]. In the present study, we have evaluated the binding of plasminogen and t-PA with different modified fibrin surfaces, and the interactions occurring between these two proteins during the formation of the so-called ternary complex [3]. Furthermore, we have correlated the effect of cleavage of the fibrin chains by plasmin with the binding of plasminogen and $\mathrm{t}-\mathrm{PA}$ during ongoing fibrinolysis.

\section{MATERIALS AND METHODS}

\section{Chemicals and buffers}

Chromogenic substrate methylmalonylhydroxyprolylarginine $p$-nitroanilide (CBS 1065), and human thrombin were from Diagnostica Stago; aprotinin was from Behringwerke; D-valyl-L-phenylalanyl-L-lysine chloromethane (ValPheLys $\mathrm{CH}_{2} \mathrm{Cl}$ ), dansyl-glutamyl-glycyl-arginine chloromethane (Dns-GluGly $\mathrm{ArgCH}_{2} \mathrm{Cl}$ ), and D-phenylalanyl-L-prolyl-L-arginine chloromethane (PheProArgCH $\mathrm{Cl}_{2} \mathrm{Cl}$ ) from France Biochem. All the chemicals used were of the best reagent grade commercially available. Other products were obtained as previously indicated $[19,20]$. Buffer $\mathrm{A}$ was $0.05 \mathrm{M}$ sodium phosphate $\mathrm{pH} 7.4$, containing $0.08 \mathrm{M} \mathrm{NaCl}$. Assay buffer was buffer A containing $2 \mathrm{mg}$ bovine serum albumin $/ \mathrm{ml}$ and $0.01 \%$ (by vol.) Tween 20 . Mass buffer, a buffer that provided the mass-action effects on the competitive non-specific adsorption of plasminogen to the fibrin surfaces, was buffer A containing $40 \mathrm{mg}$ bovine serum albumin/ml and $0.01 \%$ (by vol.) Tween 20. All other buffers were prepared as described in the text.

\section{Purified proteins}

Fibrinogen and Glu-plasminogen were purified from diisopropylphosphofluoridate( $\left.\mathrm{iPr}_{2} \mathrm{P}-\mathrm{F}\right)$-treated fresh-frozen human plasma by, respectively, glycine precipitation according to Kazal et al. [21], and affinity chromatography on lysineSepharose 4B [22]. Further purification was achieved as previously described $[19,20]$. The Glu-plasminogen preparation was more than $99 \%$ pure as assessed by SDS/PAGE and autoradiography of the ${ }^{125}$ I-labelled plasminogen, and by amino-terminal amino acid sequence analysis [23]. Protein concentration was measured at $280 \mathrm{~nm}$ in buffer A using $\varepsilon^{1 \%, 1 \mathrm{~cm}}$ of 15.1 [24] for fibrinogen and 16.8 for plasminogen [25].

Recombinant plasminogen with Ser741 mutagenized to Ala, [Ala741]rPg, was obtained by expression in Chinese hamster ovary cells of the plasmid plg $251 \mathrm{a} / 219 \mathrm{~b}$ [26] using the vector Zem 229 [27], and was purified from the cell culture medium by affinity chromatography on lysine-Sepharose
[22]. [Ala741] $\mathrm{rPg}$ could be converted to an inactive twochain molecule by treatment with two-chain urokinase-type plasminogen activator (tcu-PA) or with t-PA [28]. The absence of amidolytic activity of the [Ala741] rPg two-chain molecule against the tripeptide substrate S-2251 (Biogenic) was verified both in soluble phase and in an assay in which fibrin-bound [Ala741] $\mathrm{rPg}$ was treated with $10 \mathrm{U} / \mathrm{ml}$ tcu-PA.

Human t-PA ( $>95 \%$ single-chain) purified from Bowes melanoma cell-conditioned medium on immobilized monoclonal antibody anti-t-PA was from Biopool. It had a specific activity of $680000 \mathrm{U} / \mathrm{mg}$ by reference to the First International Standard for t-PA (preparation coded 83/517, National Institute for Biological Standards and Control, London) as determined with the solid-phase fibrin-t-PA photometric assay [29] using $200 \mathrm{nM}$ plasminogen and $1.5 \mathrm{mM}$ CBS 1065. iPr 2 P-F-inactivated t-PA (Dip-t-PA) was prepared by treating $14.7 \mu \mathrm{g} \mathrm{t}-\mathrm{PA}$ in $100 \mu \mathrm{l}$ buffer A with $2.7 \mathrm{mM}$ iPr $2 \mathrm{P}-\mathrm{F}$ for $15 \mathrm{~min}$ at $22^{\circ} \mathrm{C}$, diluted 100 -fold, aliquoted and stored at $-70^{\circ} \mathrm{C}$. Before use, each aliquot was again treated twice with $\mathrm{iPr}_{2} \mathrm{P}-\mathrm{F}$ (two $2.7 \mathrm{mM}$ cycles). Fibrin-bound Dipt-PA had no residual activity in the above mentioned photometric assay even after incubation for $72 \mathrm{~h}$ at $37^{\circ} \mathrm{C}$.

Plasmin was prepared by activation of plasminogen with immobilized tcu-PA, as previously described [30]. The tcuPA-free plasmin was stored at $-70^{\circ} \mathrm{C}$ in $0.1 \mathrm{M}$ sodium acetate, $\mathrm{pH} 4.0$, containing $0.3 \mathrm{M} \mathrm{NaCl}$ and $25 \%$ (mass/vol.) glycerol. Its final concentration was $13.5 \mu \mathrm{M}$ (determined by active-site titration with $p$-nitrophenyl- $p^{\prime}$-guanidinobenzoate).

Goat polyclonal antibodies (IgG) directed against human uterine t-PA, and against human plasminogen were from Biopool. The IgG fraction of these sera was purified by precipitation with $45 \%$ ammonium sulfate and chromatography on DEAE-Trisacryl. A goat anti-mouse immunoglobulin serum was submitted to the same procedure and the IgG were further purified by affinity chromatography on a mouse immunoglobulin immunoadsorbent.

A mAb (FDP-14, IgG1, $\kappa$ ), raised against physiological fibrin-degradation products, that recognizes an epitope containing the sequence $54-118$ of the $\mathrm{B} \beta$ chain of fibrinogen was prepared as described [31].

\section{Preparation of proteinase-treated fibrin surfaces}

Solid-phase fibrin was prepared as previously described $[29,32]$ with minor modifications $[19,20]$. The cleavage of fibrinopeptide $A$ by thrombin was verified by the disappearance of immunoreactivity with a mouse $\mathrm{mAb}, \mathrm{Y} 18$, directed against the $\mathrm{A} \alpha$ sequence $1-51$ of human fibrinogen [33]. The plate thus prepared was treated with $25 \mathrm{nM}$ plasmin for $30 \mathrm{~min}$ at $37^{\circ} \mathrm{C}$ and fibrin-bound plasmin was eluted in buffer A containing $0.2 \mathrm{M}$ trans-4-(aminomethyl)-cyclohexane carboxylic acid, $1 \mathrm{mM}$ benzamidine and $10 \mu \mathrm{M}$ ValPhe$\mathrm{LySCH}_{2} \mathrm{Cl}$ as previously indicated [19]. No significant amidolytic activity was detected after incubation of the degraded surface with $1.5 \mathrm{mM}$ CBS 1065 for $48 \mathrm{~h}$ at $37^{\circ} \mathrm{C}$. Degradation of the surface of fibrin by plasmin was demonstrated by the binding of the mAb FDP-14 [31] which does not react with intact fibrin. In some experiments, the carboxy-terminal lysine residues generated on the plasmin-treated fibrin surface were removed by treatment with $50 \mu \mathrm{g} / \mathrm{ml}$ carboxypeptidase $\mathrm{B}$ for $2 \mathrm{~h}$ at $37^{\circ} \mathrm{C}$ in $0.05 \mathrm{M}$ Hepes, $\mathrm{pH} 7.5,0.5 \mathrm{M} \mathrm{NaCl}$ and $10 \mu \mathrm{M} \mathrm{ZnCl}_{2}$. The intact fibrin surface was submitted to a similar treatment with carboxypeptidase B to ensure complete absence of carboxy-terminal lysine or arginine residues 
on this surface. All the following experiments were performed in a reaction volume of $50 \mu \mathrm{l} /$ well.

\section{Binding of plasminogen and t-PA to the fibrin surfaces}

Varying amounts of native plasminogen or [Ala741] $\mathrm{rPg}$ containing a trace amount of their respective ${ }^{125}$ I-labelled forms were prepared in mass buffer, incubated to equilibrium for $18 \mathrm{~h}$ at $4^{\circ} \mathrm{C}$ with different fibrin surfaces previously washed three times with assay buffer. The incubation mixtures were then removed, the plate washed three times with assay buffer, and the radioactivity bound to each well was analysed in a $\gamma$-radiation counter.

The binding of t-PA to different surfaces of fibrin was performed as follows. Solutions of native or Dip-t-PA were prepared in mass buffer and incubated with fibrin surfaces for $18 \mathrm{~h}$ at $4^{\circ} \mathrm{C}$. After washing the plates, the binding of t-PA was detected with a ${ }^{125} \mathrm{I}-\mathrm{IgG}$ directed against t-PA $\left(8 \times 10^{5} \mathrm{dpm} /\right.$ well in mass buffer $)$ incubated for $1 \mathrm{~h}$ at $37^{\circ} \mathrm{C}$. The plate was washed and the radioactivity bound to each well was counted in a $\gamma$-radiation counter [Wallac LKB (counting efficiency $=63 \%$ )]. In some experiments performed with active t-PA, the amount of t-PA bound to the fibrin surface was detected by adding $200 \mathrm{nM}$ of plasminogen and $1.5 \mathrm{mM}$ of CBS 1065 . Under these conditions, the initial velocity of the cleavage of the synthetic substrate was directly proportional to the amount of bound $t-P A$, as previously described [29].

\section{Competition experiments between plasminogen and t-PA}

Two experimental procedures were used to analyze the competitive binding of t-PA and plasminogen to fibrin. In the first type of experiment, an intact surface of fibrin was saturated with $4 \mathrm{nM}$ Dip-t-PA for $1 \mathrm{~h}$ at $37^{\circ} \mathrm{C}$ before adding increasing concentrations $(0-10 \mu \mathrm{M})$ of plasminogen. The binding of plasminogen to the intact fibrin surface was detected with a ${ }^{125} \mathrm{I}-\mathrm{IgG}$ polyclonal antibody directed against plasminogen $\left(8 \times 10^{5} \mathrm{dpm} /\right.$ well $)$ and expressed in $\mathrm{dpm}$ bound/well. In the second type of experiment, the binding to intact or degraded fibrin surfaces of $4 \mathrm{nM}$ Dip-t-PA in the presence of $0-10 \mu \mathrm{M}$ native plasminogen prepared in mass buffer supplemented with $1 \mu \mathrm{M}$ Dns-GluGlyArgCH $\mathrm{H}_{2} \mathrm{Cl}$, or $1 \mathrm{nM}$ [Ala741]rPg in the presence of $0-20 \mathrm{nM}$ native t-PA, was measured. The plasminogen solutions contained a trace amount of their respective ${ }^{125}$ I-plasminogen forms and the binding was quantified as described above. In a control experiment, we measured the binding of native plasminogen $(18 \mathrm{nM})$ in the presence of increasing concentrations of active t-PA in order to quantify the evolution of plasminogen-binding sites during plasminogen activation for $1 \mathrm{~h}$ at $37^{\circ} \mathrm{C}$. Plasmin(ogen) binding was quantified as described above. In parallel, proteins bound to the fibrin surface were eluted by three washes with assay buffer containing $0.2 \mathrm{M}$ trans-4-(aminomethyl)-cyclohexane carboxylic acid, $1 \mathrm{mM}$ benzamidine and $10 \mu \mathrm{M}$ ValPhe $\mathrm{LysCH}_{2} \mathrm{Cl}$. The extent of the fibrin degradation was then detected by incubating $200 \mathrm{ng} /$ $\mathrm{ml}$ of FDP-14 in mass buffer for $2 \mathrm{~h}$ at $37^{\circ} \mathrm{C}$. After three washes of the plate with assay buffer, a goat anti-mouse ${ }^{125} \mathrm{I}-$ IgG in mass buffer was used for detection. Finally, the plate was washed and the bound radioactivity was counted in a $\gamma$ radiation counter.

\section{Radiolabelling of proteins}

Native Glu-plasminogen or [Ala741]rPg and the polyclonal IgG directed against either plasminogen, $t$-PA or the mouse $\mathrm{IgG}$, were radiolabelled with $\mathrm{Na}\left[{ }^{125} \mathrm{I}\right]$ with the use of the Iodogen ${ }^{\mathrm{TM}}$ method of Fraker and Speck [34] with the following modifications. Protein $(10 \mu \mathrm{g}$ in $0.2 \mathrm{M}$ sodium phosphate $\mathrm{pH} 7.4$ ) and $0.5 \mathrm{mCi}$ of the radioisotope were added ( $15 \mu$ l final volume) to a conical plastic centrifuge vial (Eppendorf) coated with Iodogen ${ }^{\mathrm{TM}}(10 \mu \mathrm{g})$ according to the manufacturer's instructions. After an iodination time of 4 min at $4^{\circ} \mathrm{C}$, the labelled protein was separated from free $\mathrm{Na}\left[{ }^{125} \mathrm{I}\right]$ by gel filtration on a PD-10 Sephadex G-25 column (medium grade). The specific activities obtained were 3$8 \mathrm{Ci} / \mathrm{g}$ Glu-plasminogen, $17-25 \mathrm{Ci} / \mathrm{g}$ [Ala741] $\mathrm{rPg}$, and 20$35 \mathrm{Ci} / \mathrm{g}$ IgG. The labelled native plasminogen was identical to the unlabelled product as assessed by a residual activity of $85-100 \%$ after activation with fibrin-bound t-PA.

\section{Analysis of binding data}

Untransformed data were analyzed by non-linear regression methods. The average binding curves for plasminogen or t-PA interaction with fibrin fitted the simple Langmuir equation for adsorption at interfaces. The equilibrium association constant $(K)$ and the total number of binding sites $\left(B_{\max }\right)$ were derived from the linearized expression of the Langmuir equation as previously described [19].

\section{RESULTS}

\section{Binding of plasminogen or $\mathrm{iPr}_{2} \mathrm{P}$-F-inactivated $\mathrm{t}$-PA (Dip-t-PA) to an intact fibrin surface}

To determine if the presence of t-PA promotes the binding of plasminogen to an intact surface of fibrin, the surface was saturated with Dip-t-PA, an inactivated form of t-PA that prevents plasmin generation. The binding of increasing con centrations of plasminogen to intact fibrin or to fibrin saturated with Dip-t-PA is represented in Fig. 1. Neither the affinity nor the $B_{\max }$ of plasminogen was modified by the previous binding of t-PA: $K_{\mathrm{d}}=0.91 \mu \mathrm{M}$ on fibrin alone and $1.06 \mu \mathrm{M}$ on fibrin with Dip-t-PA. These $K_{\mathrm{d}}$ values are in accordance with those obtained previously, i.e. $0.99 \pm 0.17 \mu \mathrm{M}$ [19]. Moreover, competitive binding experiments between Dip-t-PA and plasminogen (Fig. 1) showed that the binding of Dip-t-PA (input concentration of $4 \mathrm{nM}$ ) to intact fibrin was not modified by increasing concentrations of plasminogen $(0-10 \mu \mathrm{M})$. In the alternative experiment (data not shown), the fibrin-bound plasminogen, upon incubation with $1 \mathrm{nM}$ plasminogen, was not displaced by $\mathrm{t}-\mathrm{PA}$ even at a concentration of $20 \mathrm{nM}$. All these data indicate that binding of plasminogen and t-PA to intact fibrin occurs via totally independent mechanisms.

\section{Interactions of active t-PA and native or [Ala741]rPg with fibrin}

Native plasminogen or [Ala741] rPg were allowed to bind to the intact fibrin surface in the presence of increasing concentrations $(0-20 \mathrm{nM})$ of active t-PA (Fig. 2). Whereas the binding of plasmin(ogen) at an input of $18 \mathrm{nM}$ increases 25 fold in $1 \mathrm{~h}$ at $37^{\circ} \mathrm{C}$ already at a concentration of $4 \mathrm{nM} \mathrm{t}$-PA, the binding of [Ala741] rPg was not significantly modified even after $18 \mathrm{~h}$ at $22^{\circ} \mathrm{C}$ at the highest t-PA concentration used in this experiment $(20 \mathrm{nM}$, Fig. 2A). Cleavage of [Ala741] $\mathrm{rPg}$ by t-PA resulted in an inactive two-chain form of plasmin that does not degrade fibrin; in contrast, cleavage 


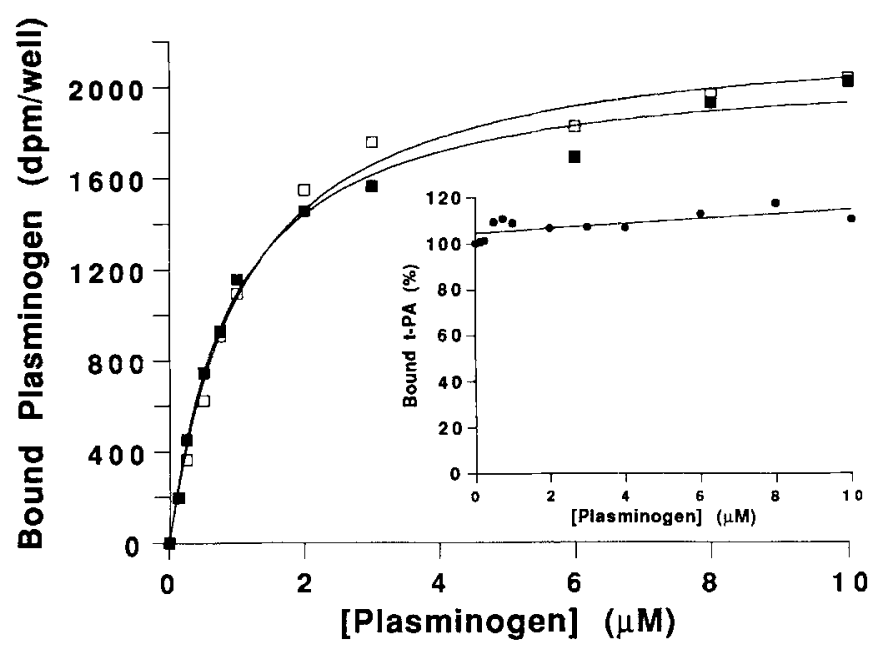

Fig. 1. Interactions of plasminogen and Dip-t-PA with intact fibrin monolayer surfaces. An intact fibrin surface was incubated with $4 \mathrm{nM}$ of Dip-t-PA in mass buffer for $1 \mathrm{~h}$ at $37^{\circ} \mathrm{C}$. After washing the plate to remove unbound Dip-t-PA, plasminogen in mass buffer supplemented with $1 \mu \mathrm{M}$ Dns-GluGlyArgCH $\mathrm{CH}_{2} \mathrm{Cl}$ was allowed to bind for $18 \mathrm{~h}$ at $4^{\circ} \mathrm{C}$. After washing the plate, the binding of plasminogen was detected with a solution of ${ }^{125} \mathrm{I}-\mathrm{IgG}$ directed against plasminogen $\left(8 \times 10^{5} \mathrm{dpm} /\right.$ well $)$ incubated for $1 \mathrm{~h}$ at $37^{\circ} \mathrm{C}$. The radioactivity bound to each well was counted and the binding of plasminogen expressed in $\mathrm{dpm} /$ well. The figure represents binding isotherms of plasminogen in the absence ( $\boldsymbol{a}$ ) and in the presence ( $\square)$ of Dip-t-PA. The inset shows Dip-t-PA $(4 \mathrm{nM})$ incubated with fibrin surfaces in the presence of increasing amounts of plasminogen for $18 \mathrm{~h}$ at $4^{\circ} \mathrm{C}$. The binding of Dip-t-PA was detected with an ${ }^{125} \mathrm{I}-$ IgG directed against t-PA incubated for $1 \mathrm{~h}$ at $37^{\circ} \mathrm{C}$ and expressed as a percentage of the maximal binding in the absence of plasminogen.

of native plasminogen yielded active plasmin as indicated by the extent of fibrin degradation quantified with the monoclonal antibody FDP-14. This antibody detects a plasmin-degradation-product-specific epitope in the fibrin E-domain. The isotherms of the binding of FDP-14 to fibrin surfaces previously incubated with t-PA and either native plasminogen or [Ala741] $\mathrm{rPg}$ were obtained after washing the plates with $0.2 \mathrm{M}$ 6-AHA and are shown in Fig. 2B. The absence of binding of FDP-14 to the surface treated with the t-PA/ [Ala741] rPg mixture illustrates that fibrin was not degraded and confirms that the plasmin generated was inactive; in contrast, the hyperbolic binding isotherm of FDP-14 obtained with the surface that was incubated with native plasminogen and t-PA indicates that fibrin had been degraded by the plasmin generated. Indeed, a linear correlation $(r=0.98)$ between the increase in the binding of plasmin(ogen) and the progressive degradation of fibrin was calculated (Fig. 2B) from the plot of plasmin(ogen) bound versus the amount of FDP-14 bound to the degraded surface of fibrin. These data clearly show that the increase in the binding of plasminogen to fibrin in the presence of t-PA is entirely induced by plasmin digestion of fibrin, i.e. by formation of carboxy-terminal lysine residues as a result of plasmin action, and is not directly promoted by t-PA. However, t-PA has been shown to have affinity for lysine residues [13] and may compete with plasminogen for binding to the surface of fibrin. The binding of t-PA to the carboxy-terminal lysines was therefore characterized in the presence and absence of plasminogen.
A
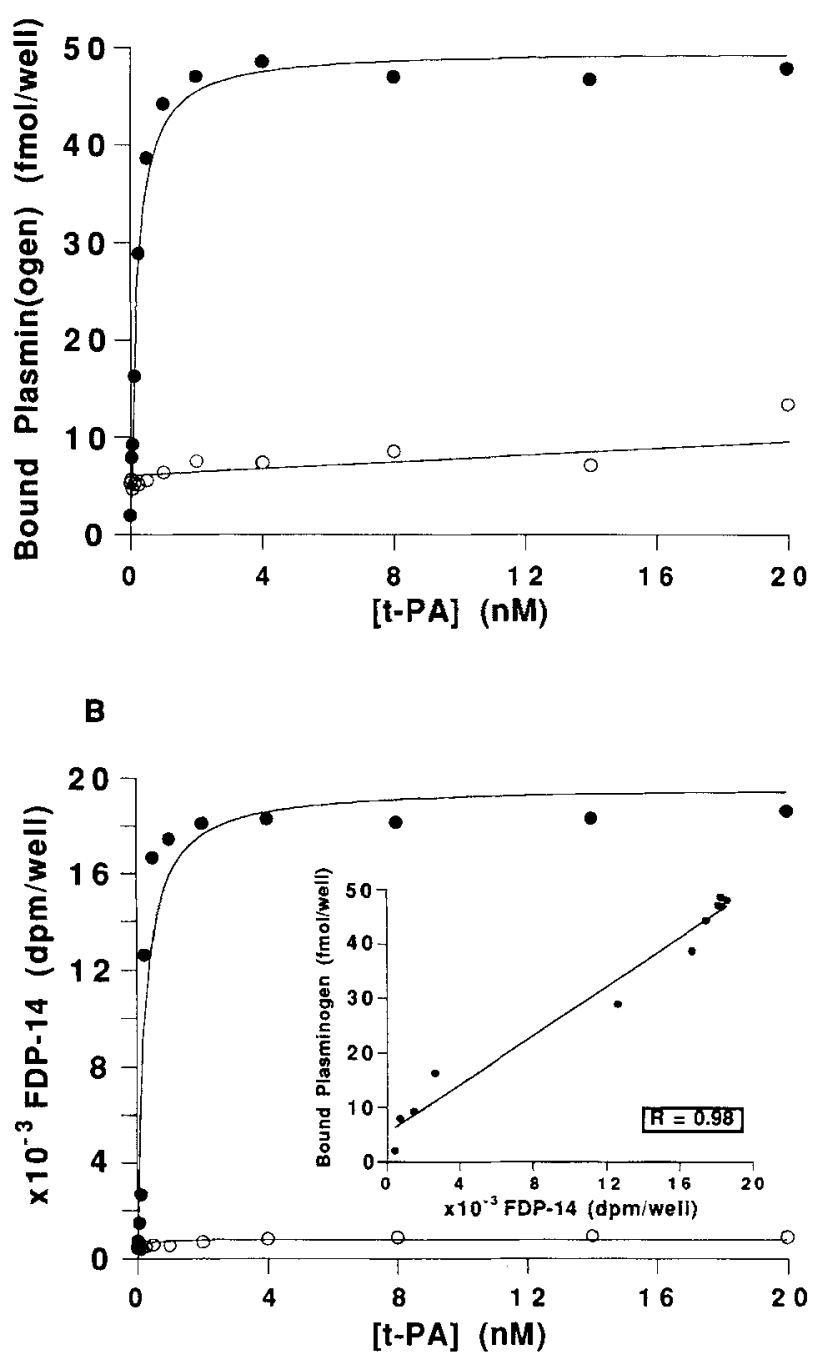

Fig. 2. Binding of plasminogen to fibrin monolayer surfaces in the presence of native $t-P A$ during ongoing fibrinolysis. Fibrin surfaces previously treated with carboxypeptidase B were incubated with a constant amount $(18 \mathrm{nM})$ of either native plasminogen (O) for $1 \mathrm{~h}$ at $37^{\circ} \mathrm{C}$ or [Ala 741$] \mathrm{rPg}(\mathrm{O})$ for $18 \mathrm{~h}$ at $22^{\circ} \mathrm{C}$, in the presence of increasing concentrations of native t-PA $(0-20 \mathrm{nM})$. After washing of the plate, the binding of plasmin(ogen) and the extent of fibrin degradation were detected. (A) Plasmin(ogen) binding isotherms. The plasminogen preparations contained a trace amount of their respective ${ }^{125}$ I-form $\left(8 \times 10^{5} \mathrm{dpm} /\right.$ well $)$. The binding of plasmin(ogen) was quantified by counting the radioactivity bound to each well, and expressed in fmol/well. (B) Detection of fibrin degradation. After removal of bound proteins from the surface as described in Materials and Methods, a solution of $200 \mathrm{ng} / \mathrm{ml}$ of FDP-14 was incubated in mass buffer for $2 \mathrm{~h}$ at $37^{\circ} \mathrm{C}$. The binding of FDP-14, a measure of the extent of fibrin degradation, was detected with a goat anti(mouse IgG) ${ }^{125}$ I-antibody $\left(2.3 \times 10^{5} \mathrm{dpm} /\right.$ well $)$, and expressed in $\mathrm{dpm} /$ well. The inset represents the correlation curve of the binding of native plasminogen versus the binding of FDP-14.

\section{Characterization of the binding of Glu-plasminogen and Dip-t-PA to intact or modified fibrin surfaces}

Results for the specific binding of native Glu-plasminogen to intact and plasmin-modified fibrin (Fig. 3) were as previously characterized [19]. The dissociation constants $\left(K_{\mathrm{d}}\right)$ of the plasminogen/fibrin interaction were determined and 


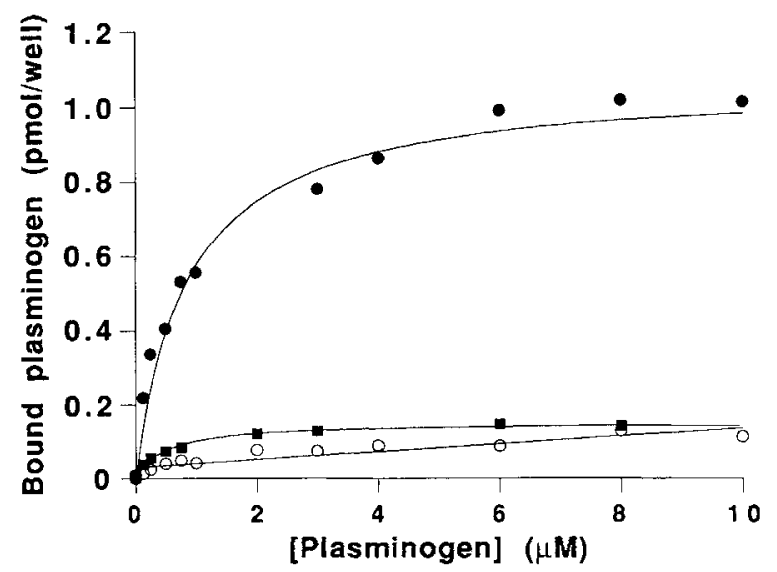

Fig. 3. Binding of native Glu-plasminogen to fibrin monolayer surfaces. Increasing concentrations of plasminogen $(0-10 \mu \mathrm{M})$ were incubated in the presence of a constant concentration of ${ }^{125} \mathrm{I}-$ plasminogen $\left(3.74 \mathrm{nM} ; 7.9 \times 10^{5} \mathrm{dpm} /\right.$ well $)$ in mass buffer for $18 \mathrm{~h}$ at $4{ }^{\circ} \mathrm{C}$ with intact fibrin ( $)$, plasmin-degraded fibrin (O) and plasmin-degraded fibrin treated with carboxypeptidase B $(\mathrm{O})$. After washing the plate three times with assay buffer, the radioactivity bound/well was counted and expressed in pmol plasminogen bound/ well by dividing the measured radioactivity by the specific radioactivity of each plasminogen solution.

were of the same order of magnitude with intact or with degraded fibrin $\left(K_{\mathrm{d}}=0.49 \mu \mathrm{M}\right.$ on fibrin and $0.86 \mu \mathrm{M}$ on degraded fibrin). In contrast, a dramatic increase in the total number of binding sites $\left(B_{\text {nax }}\right)$ was observed after treatment of the fibrin surface with plasmin $\left(B_{\max }=0.15 \mathrm{pmol}\right.$ on fibrin and $1.07 \mathrm{pmol}$ on degraded fibrin $/ 0.365 \mathrm{pmol}$ fibrin). Futhermore, the treatment of the degraded surface with carboxypeptidase $\mathrm{B}$ totally abolished the binding of plasminogen, indicating that internal lysine residues available in intact fibrin were converted to carboxy-terminal lysines by plasmin. These results clearly indicate that carboxy-terminal lysine residues of plasmin-digested fibrin represent a single type of binding site for plasminogen on such a surface.

A Bjerrum plot, $[t-P A \cdot F n]=f(\log [t-P A])$, of data obtained for the binding of Dip-t-PA to the intact or the plasmin-digested fibrin (Fn) showed saturation at more than $4 \mathrm{nM}$ of Dip-t-PA. Therefore, data were analyzed using the simple Langmuir equation for adsorption at interfaces:

$$
[\mathrm{t}-\mathrm{PA} \cdot \mathrm{Fn}]=\mathrm{Fn}_{\mathrm{o}} \frac{K[\mathrm{t}-\mathrm{PA}]}{1+K[\mathrm{t}-\mathrm{PA}]}
$$

where $[t-P A \cdot F n]$ represents the fraction of the Dip-t-PA molecules bound to fibrin, $\mathrm{Fn}_{\mathrm{o}}$ the total number of binding sites for t-PA on the fibrin surface, [t-PA] the equilibrium concentration of t-PA, and $K$ the equilibrium constant of the interaction. Using this analysis, we assume a single-site binding mechanism, and the affinity was expressed as $K_{\mathrm{d}}=1 / K$. A $K_{\triangleleft}$ value of $3.3 \pm 0.6 \mathrm{nM}$ for intact fibrin and $1.2 \pm 0.4 \mathrm{nM}$ for degraded fibrin were thus calculated (Fig. 4). These values are three orders of magnitude lower than those obtained for plasminogen and constitute a quantitative measure of the higher affinity of t-PA for fibrin. The $B_{\max }$ value for the binding of t-PA to fibrin was only slightly modified by plasmin, a 1.5 -fold increase (mean of three independent determinations) compared to the 8 -fold increase for the binding of plasminogen at saturation, and decreased to the values of intact fibrin after treatment of the degraded surface with carboxypepti-

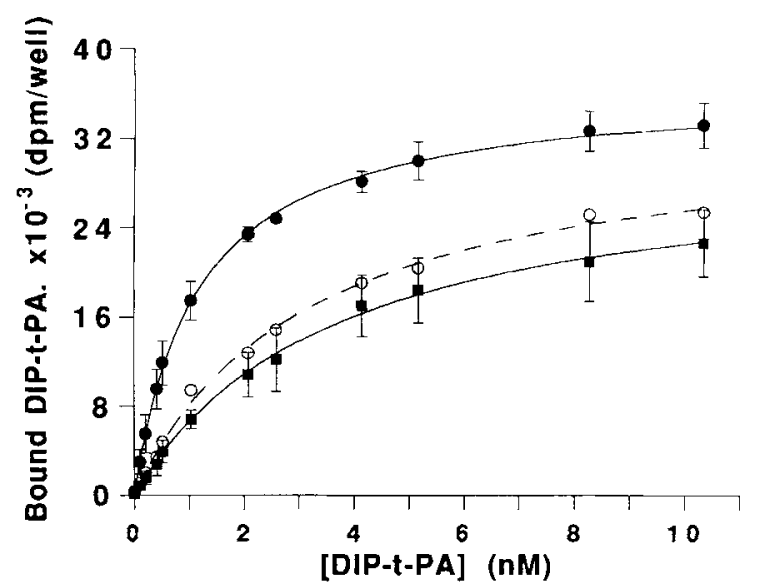

Fig. 4. Binding of Dip-t-PA to fibrin monolayer surfaces. Increasing concentrations of Dip-t-PA $(0-10 \mathrm{nM})$ were incubated in mass buffer for $18 \mathrm{~h}$ at $4{ }^{\circ} \mathrm{C}$ with intact fibrin ( $\left.\mathbf{D}\right)$, plasmin-degraded fibrin (O), and plasmin-degraded fibrin treated with carboxypeptidase B ( $O$, dotted line). The t-PA solutions were then discarded, the plate was washed three times with assay buffer before adding ${ }^{125} \mathrm{I}-\operatorname{IgG}$ polyclonal antibody diluted in mass buffer $\left(8 \times 10^{5} \mathrm{dpm} /\right.$ well $)$ and incubated for $1 \mathrm{~h}$ at $37^{\circ} \mathrm{C}$. After washing the plate, the radioactivity was counted and the amount of Dip-t-PA bound expressed in dpm/ well. Results are mean $\pm S D$ of three independent experiments performed in duplicate.

dase $\mathrm{B}$. These results clearly indicate that the high-affinity binding sites for t-PA present on intact fibrin are not modified by plasmin and that the moderate increase in the binding of t-PA to degraded fibrin depends on the presence of carboxy-terminal lysine residues formed by plasmin. However, the increase in the binding of t-PA to these residues is rather weak and this suggests that carboxy-terminal lysine residues may play only a minor role, if any, in the binding of t-PA to a plasmin-digested surface of fibrin. To further verify this hypothesis, competition experiments between plasminogen and t-PA with a degraded surface of fibrin were performed.

\section{Competition experiments between plasminogen and native or Dip-t-PA for binding to plasmin-degraded fibrin}

As shown in Fig. 5, increasing concentrations of plasminogen easily displace the supplementary binding to fibrin of a saturating concentration of Dip-t-PA $(4 \mathrm{nM})$ incubated with plasmin-digested fibrin; $50 \%$ of the binding of t-PA to the carboxy-terminal lysine residues, i.e. the difference between intact and degraded fibrin, was inhibited with $0.93 \mu \mathrm{M}$ plasminogen. However, no inhibition of the binding of plasminogen (Fig. 5) could be observed by increasing concentrations of Dip-t-PA. Similar results were obtained whether a limited amount of plasminogen $(1 \mathrm{nM})$ or a concentration close to the $K_{\mathrm{c}}$ value on degraded fibrin $(1 \mu \mathrm{M})$ was used.

To exclude any bias in the competition experiments that may be caused by the use of Dip-t-PA instead of the native molecule or by a trace amount of active t-PA in the mixture, similar experiments were performed using native t-PA and the mutant plasminogen [Ala741] rPg. The results are illustrated in Fig. 6. The binding of $1 \mathrm{nM}$ [Ala741] rPg to the degraded fibrin surface remained constant in the presence of increasing concentrations of t-PA. The concomitant binding of t-PA in the course of this experiment was verified (Fig. 6). 


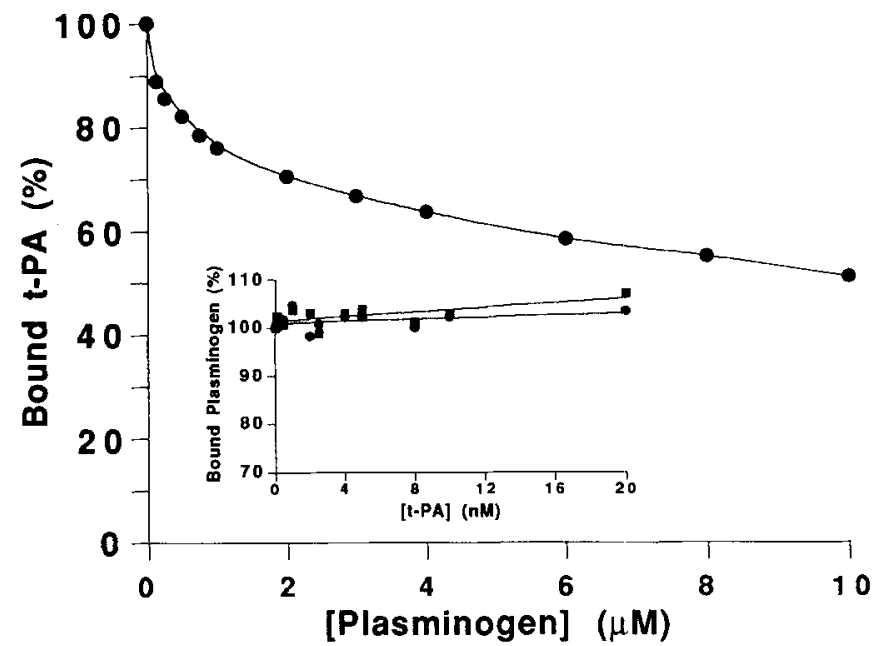

Fig. 5. Competition experiments between plasminogen and Dipt-PA for hinding to plasmin-degraded fibrin monolayers. Dip-tPA (4 nM) was incubated with fibrin surfaces in the presence of increasing amounts of plasminogen for $18 \mathrm{~h}$ at $4{ }^{\circ} \mathrm{C}$. The binding of Dip-t-PA was detected with an ${ }^{125} \mathrm{I}-\mathrm{IgG}$ directed against t-PA incubated for $1 \mathrm{~h}$ at $37^{\circ} \mathrm{C}$ and expressed as a percentage of the maximal binding in the absence of plasminogen. The inset represents the alternative experiment in which $1 \mathrm{nM}(\mathbf{O})$ or $1 \mu \mathrm{M}(\boldsymbol{D})$ of plasminogen was incubated in the presence of increasing concentrations of Dip-t-PA $(0-20 \mathrm{nM})$. The binding of plasminogen was detected with ${ }^{225} \mathbf{I}-\mathrm{IgG}$ directed against plasminogen as described in Fig. 1 and expressed as a percentage of the maximal binding in the absence of Dip-t-PA.

Even beyond a saturating concentration of t-PA, no inhibition of the binding of plasminogen could be detected, indicating first, that t-PA was unable to compete for plasminogen-binding sites on degraded fibrin, and secondly, that binding of t-PA to the carboxy-terminal lysine residues of this surface is impaired by plasminogen.

\section{DISCUSSION}

Fibrin-catalyzed generation of plasmin involves diffusion from plasma and adsorption to the surface of a clot of plasminogen and t-PA. Indeed, as proposed by Krause and Deutsch [2], molecules of the fibrin gel located inside the clot are still intact at the time the exterior surface has already been extensively degraded. Hoylaerts et al. [3] have proposed that the binding of these proteins to fibrin follows a sequentially ordered mechanism producing a stable cyclic ternary complex. In addition, Tran-Thang et al. [15] reported indirect evidence suggesting that the increased uptake of Glu-plasminogen onto clots observed in the presence of t-PA was mediated by limited-degradation of fibrin by plasmin. However, in their experiments neither the extent of degradation of the surface of the clot was verified nor the nature of the binding sites was identified. We have presently re-investigated and further characterized the assembly of fibrinolytic proteins during plasminogen activation using a well-defined model of an immobilized surface of fibrin. Since the monolayer of fibrinogen from which the fibrin surface is generated was covalently bound to the support, most of the fibrin fragments remain in situ thus allowing identification and quantification of the progressive degradation of fibrin with FDP-

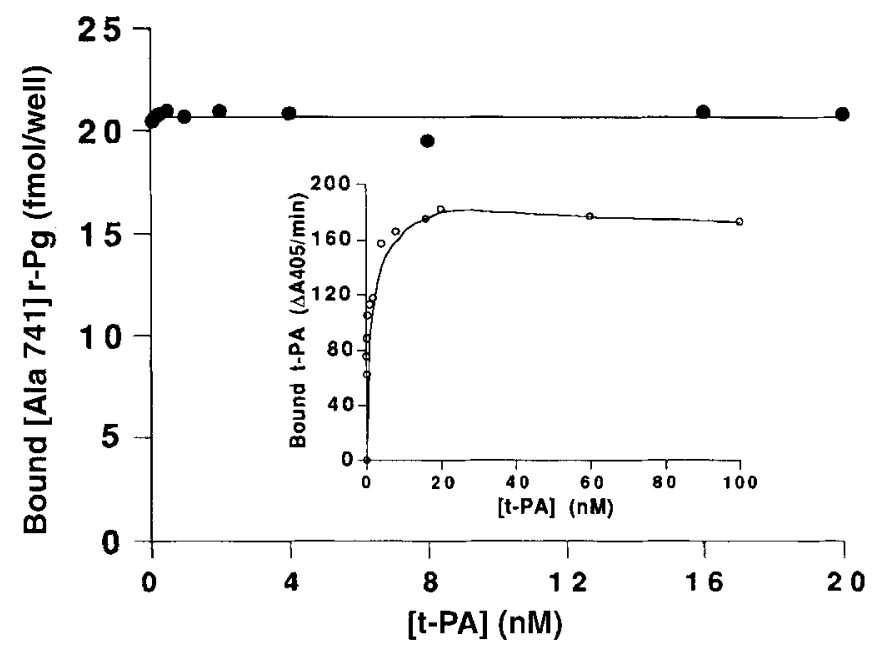

Fig. 6. Competition binding experiments between [Ala741]rPg and native t-PA on plasmin-degraded fibrin monolayers. $A$ constant amount of ${ }^{125} \mathrm{I}-[\mathrm{Ala} 741] \mathrm{rPg}\left(1 \mathrm{nM}, 2 \times 10^{5} \mathrm{dpm} / \mathrm{well}\right)$ was incubated on degraded fibrin with increasing concentrations of native t-PA $(0-20 \mathrm{nM}$, i.e. $0-966 \mathrm{U} / \mathrm{ml})$ for $18 \mathrm{~h}$ at $4^{\circ} \mathrm{C}$. The plate was washed, and the radioactivity of the wells was counted in a $\gamma$-radiation counter. Bound radioactivity was transformed into fmol plasminogen bound/well. The inset represents the concomitant binding of t-PA in the presence of [Ala 741]rPg. After washing the plate, the binding of t-PA was detected by addition of $200 \mathrm{nM}$ native plasminogen and $1.5 \mathrm{mM}$ CBS 1065, and photometrically monitoring of the cleavage of the synthetic substrate by generated plasmin in a microtitration plate counter (MR 5000, Dynatech) at double wavelength absorbance ratio $\left(A_{405} / A_{491}\right)$. The amount of $\mathrm{t}-\mathrm{PA}$ bound/well is expressed in $\Delta A_{405} / \mathrm{min}$.

14 , a monoclonal antibody that specifically reacts with fibrin degradation products but not with intact fibrin. This model has been previously used to quantify the binding of Gluplasminogen and Lys-plasminogen to fibrin [19].

In the present work we have confirmed the finding [15] that Dip-t-PA does not increase the binding of plasminogen to the fibrin surface and that active $\mathrm{t}-\mathrm{PA}$ is required to induce an enhancement in the number of bound plasmin(ogen) molecules. In the presence of Dip-t-PA bound Glu-plasminogen and fibrin remained intact while in the presence of active t-PA most of the bound molecules were converted to plasmin, and fibrin was degraded as shown by using the monoclonal antibody FDP-14. Since conversion of single-chain t-PA to two-chain t-PA, and Glu-plasminogen to Lys-plasminogen by plasmin thus formed may also influence the binding of plasminogen to fibrin, the role played by the active site of t-PA in functional isolation was further characterized using active t-PA and a recombinant plasminogen mutant which is inactive after conversion to two-chain plasmin. In this case, the binding of the inactive two-chain plasmin did not increase and the fibrin surface was not degraded. These data constitute direct evidence establishing that plasmin and not t-PA is responsible for the increased binding of plasminogen to the fibrin surface during ongoing fibrinolysis, and that the increased binding of plasminogen is directly related to progressive plasmin-mediated generation of fibrin-degradation fragments with carboxy-terminal lysine residues.

In a recent study, Lijnen et al. [28] have shown that the rate of activation of [Ala741] $\mathrm{rPg}$ by t-PA in the presence of cyanogen bromide fragments of fibrinogen was 20 -fold lower than the activation of native plasminogen. The present 
studies demonstrate directly (close correlation between fibrin degradation and plasminogen binding to carboxy-terminal lysine residues) that plasminogen activation may be decreased by the impaired generation of carboxy-terminal lysine residues due to the absence of active plasmin. Further support to this conclusion was recently provided by data indicating that $\alpha_{2}$-antiplasmin efficiently inhibits fibrinolysis by preventing generation of carboxy-terminal lysine residues by plasmin released from the evolving surface of fibrin [35].

Two binding sites for t-PA have been localized in the Ddomains of fibrin(ogen) $[36,37]$. However, the kringle type2 domain of t-PA may also interact with lysine residues in fibrin [18]. We have therefore evaluated the possibility that competition with plasminogen for these sites may be an important step in the progression of fibrinolysis. Indeed, on the basis of their sensitivity to carboxypeptidase $B$ we have detected two types of binding sites for t-PA on fibrin degraded by plasmin. Parameters of the binding of $t-P A$ to intact fibrin and to carboxypepdidase-B-treated degraded fibrin were identical indicating that the first type of binding sites are already present in intact fibrin and are not modified by plasmin, and that the second type of binding sites are entirely constituted by carboxy-terminal lysine residues. Since both binding sites for t-PA coexist on fibrin degraded by plasmin it was impossible to differentiate the affinity for lysine residues from the affinity for sites present in intact fibrin. The latter are probably mediated by interactions with the finger domain $[5,6]$. The $K_{\mathrm{d}}$ value of t-PA for intact fibrin was three orders of magnitude lower $\left(10^{-9} \mathrm{M}\right)$ than the $K_{\mathrm{d}}$ value of Glu-plasminogen for both intact or degraded fibrin $\left(10^{-6} \mathrm{M}\right)$. However, binding of t-PA to these sites was displaced by plasminogen indicating that the affinity of t-PA for carboxy-terminal lysine residues must be lower than the affinity of plasminogen. These results are in agreement with studies indicating that the affinity of t-PA for lysine residues is considerably lower than the affinity of plasminogen [38, 39]. Indeed, Kelley et al. [13] have shown that the affinity of the t-PA kringle 2 domain for either L-lysine or 6-AHA is extremely low $\left(K_{\mathrm{d}}=62 \mu \mathrm{M}\right)$.

The difference in affinity between plasminogen and t-PA for degraded fibrin can easily explain the results obtained in competitive experiments performed between these molecules on this surface. De Vries et al. [40] have shown that the binding of plasminogen (input $=0.5 \mathrm{nM}$ ) could be displaced by increasing concentrations of t-PA $(0-12 \mu \mathrm{M})$. In our experiments, the concentrations of t-PA used were lower and, according to the low affinity of t-PA for carboxy-terminal lysines, we have only detected an inhibition of approximately $10 \%$ in the binding of plasminogen using $100 \mathrm{nM} \mathrm{t}-\mathrm{PA}$, a concentration equivalent to $5000 \mathrm{U} / \mathrm{ml}$ (data not shown). All these data clearly indicate that t-PA can bind to carboxyterminal lysine residues of a degraded fibrin surface only in the absence of plasminogen. This binding is efficiently competed by plasminogen $\left(C_{50 \%}=0.93 \mu \mathrm{M}\right)$ and consequently would not exist at the physiological plasminogen concentration in plasma $(1.5 \mu \mathrm{M})$.

Altogether, our results indicate that the binding of plasminogen and t-PA to intact fibrin are independent, and demonstrate that the generation of fibrin degradation fragments during ongoing fibrinolysis does not represent potential physiological binding sites for t-PA. We also conclude that in a plasma milieu, where the concentration of plasminogen is higher than $1 \mu \mathrm{M}$, one of the main mechanisms in enhancement of the fibrinolytic process involves an increase in high-affinity binding sites for plasminogen.
We are very grateful to Drs $\mathrm{S}$. Busby and G. Parker (ZymoGenetics, Seattle, WA) for supplying the plasmid plg $251 \mathrm{a} / 219 \mathrm{~b}$ and the vector Zem 229. We are indebted to Dr T. Lambert (Blood Bank, Hôpital de Bicêtre) for providing fresh-frozen human plasma for the purification of plasminogen and fibrinogen. This work was supported by the Institut National de la Santé et de la Recherche Médicale. V. F. was a recipient of a scholarship from the Ministère de la Recherche et de la Technologie and was supported in part by a grantin-aid from the Fondation Singer-Polignac.

\section{REFERENCES}

1. Wiman, B. \& Collen, D. (1978) Eur. J. Biochem. 84, 573-578.

2. Krause, J. \& Deutsch, H. (1989) Fibrinolysis 3, 85-91.

3. Hoylaerts, M., Rijken, D., Lijnen, H. R. \& Collen, D. (1982) J. Biol. Chem. 257, 2912-2919.

4. Sottrup-Jensen, L., Claeys, H., Zaydel, M., Petersen, T. E. \& Magnusson, S. (1978) Progress in chemical fibrinolysis and thrombolysis, 3rd edn, pp. 191-209, Raven Press, New York.

5. Van Zonneveld, A., Veerman, H. \& Pannekoek, H. (1986) Proc. Natl Acad. Sci. USA 83, 4670-4674.

6. Verheijen, J. H., Caspers, M. P. M., Chang, G. T. G., De Munk, G. A. W., Pouwels, P. H. \& Enger-Valk, B. E. (1986) EMBO J. 5, 3525-3530.

7. Thorsen, S., Clemmensen, I., Sottrup-Jensen, L. \& Magnusson, S. (1981) Biochim. Biophys. Acta 668, 377-387.

8. Vali, Z. \& Patthy, L. (1982) J. Biol. Chem. 257, 2104-2110.

9. De Marco, A., Petros, A. M., Laursen, R. A. \& Llinas, M. (1987) Eur. Biophys. J. 14, 359-368.

10. Menhart, N., Sehl, L. C., Kelley, R. F. \& Castellino, F. J. (1991) Biochemistry 30, 1948-1957.

11. Christensen, U. (1984) Biochem. J. 223, 413-421.

12. Christensen, U. (1985) FEBS Lett. 182, 43-46.

13. Kelley, R. F., De Vos, A. M. \& Cleary, S. (1991) Proteins Struct. Funct. Genet. 11, 35-44.

14. Suenson, E., Lutzen, O. \& Thorsen, S. (1984) Eur. J. Biochem. $140,513-522$

15. Tran-Thang, C., Kruithof, E. K. O. \& Bachmann, F. (1984) $I$. Clin. Invest. 74, 2009-2016.

16. Tran-Thang, C., Kruithof, E. K. O., Atkinson, J. \& Bachmann, F. (1986) Eur, J. Biochem. 160, 599-604.

17. Harpel, P. C., Chang, T. S. \& Verderber, E. (1985) J. Biol. Chem. $260,4432-4440$.

18. De Vries, C., Veerman, H. \& Pannekoek, H. (1989) J. Biol. Chem. 264, 12604-12610.

19. Fleury, V. \& Anglés-Cano, E. (1991) Biochemistry 30, 76307638.

20. Fleury, V., Gurewich, V. \& Anglés-Cano, E. (1993) Fibrinolysis 7, 87-96.

21. Kazal, L. A., Amsel, S., Miller, O. P. \& Tocantins, L. M. (1963) Proc. Soc, Exp. Biol. Med. 113, 989-994.

22. Deutsch, D. G. \& Mertz, E. T. (1970) Science 170, 1095-1096.

23. Edman, P. \& Henschen, A. (1975) in Protein sequence determination (Needleman, S. B., ed.) pp. 232-279, Springer, Berlin, Heidelberg, New York.

24. Blombäck, B. \& Blombäck, M. (1956) Ark. Kemi 10, 415-443.

25. Wallen, P. \& Wiman, B. (1972) Biochim. Biophys. Acta 257, $122-134$.

26. Busby, S. J., Mulvihill, E., Rao, D., Kumar, A. A., Lioubin, P., Heipel, M., Sprecher, C., Halfpap, L., Prunkard, D., Gambee, J. \& Foster, D. C. (1991) J. Biol. Chem. 266, 15286-15292.

27. Shapiro, R. A., Scherer, N. M., Habecker, B. A., Subers, E. M. \& Nathanson, N. M. (1988) J. Biol. Chem. 263, $18397-$ 18403.

28. Lijnen, H. R., Van Hoef, B., De Cock, F. \& Collen, D. (1990) Thromb. Haemostasis 64, 61-68.

29. Anglés-Cano, E. (1986) Anal. Biochem. 153, 201-210.

30. Wiman, B. \& Wallen, P. (1973) Eur. J. Biochem. 36, 25-31.

31. Koppert, P. W., Koopman, J., Haverkate, F. \& Nieuwenhuizen, W. (1986) Blood 68, 437-441.

32. Anglés-Cano, E. \& Sultan, Y. (1984) J. Immunol. Methods 69, $115-127$. 
33. Koppert, P. W., Huijmans, C. M. G. \& Nieuwenhuizen, W. (1985) Blood 66, 503-507.

34. Fraker, P. J. \& Speck, J. C. Jr (1978) Biochem. Biophys. Res. Commun. 80, 849-857.

35. Anglés-Cano, E., Rouy, D. \& Lijnen, H. R. (1992) Biochim. Biophys. Acta 1156, 34-42.

36. Bosma, P. J., Rijken, D. C. \& Nieuwenhuizen, W. (1988) Eur. J. Biochem. 172, 399-404.

37. Yonekawa, O., Voskuilen, M. \& Nieuwenhuizen, W. (1992) Biochem. J. 283, 187-191.
38. De Munk, G. A. W., Caspers, M. P. M., Chang, G. T. G., Pouwels, P. H., Engel-Valk, B. E. \& Verheijen, J. H. (1989) Biochemistry 28, 7318-7325.

39. Wilhelm, O. G., Jaskunas S. R., Vlahos, C. J. \& Bang, N. U. (1990) J. Biol. Chem. 265, 14606-14611.

40. De Vries, C., Veerman, H., Koornneef E. \& Pannekoek, H. (1990) J. Biol. Chem. 265, 13547-13552. 